\title{
Yaşlı Bireylerde Demografik Özelliklerin ve Huzurevinde Yaşamanın Plantar Duyuya Etkisi
}

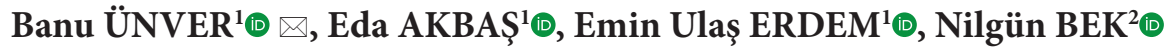 \\ ${ }^{1}$ Zonguldak Bülent Ecevit Üniversitesi, Sağlık Bilimleri Fakültesi, Fizyoterapi ve Rehabilitasyon Bölümü, Zonguldak \\ ${ }^{2}$ Hacettepe Üniversitesi, Fizik Tedavi ve Rehabilitasyon Fakültesi, Ankara
}

Bu makaleye yapılacak atıf: Ünver B, Akbaş E, Erdem EU, Bek N. Yaşlı Bireylerde Demografik Özelliklerin ve Huzurevinde Yaşamanın Plantar Duyuya Etkisi. Türk Diyab Obez 2019;1: 37-43.

\begin{abstract}
ÖZET
Amaç: Çalışmada, yaşlı bireylerde yaş, cinsiyet, obezite ve huzurevinde yaşamanın plantar hafif dokunma-basınç duyusuna etkisi incelenmiştir.

Gereç ve Yöntemler: Çalışma toplum içinde ya da huzurevinde yaşayan yaş ortalaması 74,38ะ6,59 yıl olan 60 kadın, 35 erkek olmak üzere 95 yaşı bireyle gerçekleştirildi. Bireylerin demografik özellikleri kaydedildikten sonra plantar hafif dokunma - basınç duyuları monofilament (SemmesWeinstein ${ }^{\oplus}$, NorthCoast Medical, Inc, ABD) kullanılarak ayağın dokuz bölgesinde (topuk, orta ayağın mediali, orta ayağın laterali, birinci, üçüncü ve beşinci metatars başı ile birinci, üçüncü ve beşinci parmak) değerlendirildi. Bireyler yaşadıkları yere, yaş aralıklarına, cinsiyetlerine ve vücut kütle indekslerine göre gruplara ayrılarak gruplar plantar duyu açısından karşılaştırıldı.

Bulgular: Toplum içinde yaşayanlara göre huzurevinde yaşayan yaşlıların sağ ve sol topukta; 65-75 yaşları arasında olanlara göre 75 yaş ve üstü olanların sol birinci, üçüncü ve beşinci metatarsta, sağ ve sol topukta; kadınlara göre erkeklerin sol topukta plantar hafif dokunma-basınç duyusunun azalmış olduğu bulundu $(\mathrm{p}<0,05)$. Normal, aşırı kilolu ve obez olanların plantar hafif dokunma-basınç duyuları arasında anlamlı bir fark yoktu $(\mathrm{p}>0,05)$.

Sonuç: Bu çalışma, yaşlı bireylerde ileri yaşın, erkek cinsiyetin ve huzurevinde yaşamanın plantar hafif dokunma-basınç duyusunu olumsuz etkileyebileceğini göstermiştir. Normal, aşırı kilolu ve obez yaşlı bireylerin plantar hafif dokunma-basınç duyularının benzer olduğu görülmüştür.
\end{abstract}

Anahtar Sözcükler: Yaşl, Plantar duyu, Obezite, Cinsiyet, Huzurevi

\section{Effects of Demographic Features and Living in Nursing Home on Plantar Sensitivity in Older Individuals}

\begin{abstract}
Aim: The objective of the study was to investigate the effects of age, gender, obesity, and living in nursing home on plantar light touchpressure sensitivity.

Material and Methods: The study was conducted with 95 older individuals who were living in the community or nursing home, consisting of 60 women and 35 men, mean age of $74.38 \pm 6.59$ years. Demographic characteristics of the subjects were recorded, and plantar light touch-pressure sensitivity was evaluated in nine zone of the foot (heel, medial midfoot, lateral midfoot, the first, third and fifth metatarsal head, and the first, third and fifth toe) with monofilament (SemmesWeinstein ${ }^{\circ}$, NorthCoast Medical, Inc, USA). Individuals were assigned to groups according to where they live, age ranges, gender, and body mass index, than the groups were compared in terms of plantar sensitivity.

Results: Plantar light touch-pressure sensitivity was reduced in right and left heel of the older living in nursing home than living in the community; in left first, third and fifth metatarsal and in right and left heel of older above age of 75 years than aged between 65 and 75
\end{abstract}

ORCID: Banu Ünver / 0000-0001-9758-6607, Eda Akbaş / 0000-0002-1392-1373, Emin Ulaş Erdem / 0000-0002-6736-6512, Nilgün Bek / 0000-0002-2243-5828 
years; in left heel of men than women $(\mathrm{p}<0.05)$. There were no significant difference in plantar light touch-pressure sensitivity among normal, overweight and obese subjects ( $\mathrm{p}>0.05)$.

Conclusion: This study indicated that older age, male sex and living in nursing home might have a negative effect on plantar light touch-pressure sensitivity. Plantar light touch-pressure sensitivity of the normal, overweight and obese older individuals were found to be similar.

Key Words: Older, Plantar sensitivity, Obesity, Gender, Nursing home

\section{GIIRIŞ}

Yaşlanmayla birlikte somatosensorial sistemde bozukluğun ortaya çıtığı bilinmektedir. Yaşlanma süreciyle cildin mekanik özellikleri, kutanöz reseptörlerin yoğunluğu, morfolojisi ve fizyolojisinde değişiklikler ortaya çıkar (1). $\mathrm{Bu}$ değişiklikler dokunma duyusunu da içeren kutanöz duyularin algilanmasinda progresif bir azalmaya neden olur $(2,3)$. Dokunma duyusu, çevreyle ilgili geri bildirim sağlayarak denge ve postural kontrole katkıda bulunur $(4,5)$. Ayak plantarı, ayağın ağırlık taşıdığı aktivitelerde yerle teması sayesinde yük dağılımı hakkında duyusal bilgi sağlar (5). Plantar duyu kaybının denge ve yürüyüş problemlerine neden olarak düşme riskini artırdığı bilinmektedir (3).

Yaşlanmayla birlikte plantar duyuda ortaya çıkan azalmanın 70 yaşından itibaren daha belirgin hale geldiği gösterilmiştir (6). Somatosensorial bozuklukların görülme oranı 6574 yaş arasında yaklaşık \%26, 75-84 yaş arasında \%36 ve 85 yaş üstünde \%54 civarındadır. Cinsiyetin dokunma duyusu üzerine etkisini araştıran önceki çalışmalar kadınların dokunmaya erkeklerden daha duyarlı olduğunu bildirmektedir (7). Bununla birlikte, ayağın vibrasyon alg1 eşiğinin erkeklerde daha yüksek bulunmasının kadın ve erkekler arasındaki boy uzunluğu farkından kaynaklandığı, yaş ve boya göre düzeltildiğinde cinsiyetler arasındaki vibrasyon algı eşiği farkının kaybolduğu gösterilmiştir (8).

Obezite, gelişmiş ve gelişmekte olan ülkelerde yaygınlığı giderek artmakta olan ciddi bir sağlık sorunudur (9). Obezitenin diyabet ve kardiyovasküler hastalıklar gibi kronik hastalıkların yanında kas iskelet problemleri ile de ilişkili olduğu bilinmektedir (10). Obeziteyle birlikte görülen ayağın mekanik yüklenmesindeki artış, ayak yapısında ve yürüyüşte ortaya çıkan değişiklikler gibi faktörler, plantar yük dağılımında bozulma, ayak ağrıları ve daha ileri ayak problemlerine neden olabilir (11). Plantar yüklenmenin arttığ birlikte dokunma duyusu azalır (1). Obezitenin plantar duyuya etkisini araştıran sınırlı sayıdaki araştırmaların sonuçları, obez bireylerde obez olmayanlara göre plantar dokunma ve basınç duyusunun azaldığını göstermiştir (12, 13).
Huzurevinde yaşayan yaşlıların toplum içinde yaşayanlara göre kas iskelet sistemi bozukluklarının ve fonksiyonel sorunlarının daha fazla olduğu, mobilite düzeylerinin daha düşük olduğu gösterilmiştir (14-16). Bununla birlikte bilgilerimize göre huzurevi ve toplum içinde yaşayan yaşlı bireyler arasındaki somatosensoriyal farklılıkları araştıran bir çalışma bulunmamaktadır. Bu bilgiler ışığında çalışmamızın amacı, yaşlı bireylerde yaş, cinsiyet, obezite ve huzurevinde yaşamanın plantar hafif dokunma-basınç duyusuna etkisini incelemektir. Çalışmamızın hipotezi, ileri yaş, obezite ve huzurevinde yaşamanın plantar hafif dokunma-basınç duyusunun azalmasına neden olabileceği, farklı cinsiyetler arasında plantar hafif dokunma-basınç duyusu eşiğinin farklılaşabileceğidir.

\section{GEREÇ ve YÖNTEMLER}

Bu çalışma, Bülent Ecevit Üniversitesi Sağlık Bilimleri Fakültesi Fizyoterapi ve Rehabilitasyon Bölümünde, yaş ortalaması $74,38 \pm 6,59$ yıl olan 60 kadın, 35 erkek olmak üzere 95 yaşlı bireyle gerçekleştirildi. Çalışmaya katılan bireylerden 55'i toplum içinde; 40'1 huzurevinde yaşamaktaydı. Çalışmaya 65 yaş üzeri olan, bağımsız yürüyebilen bireyler dahil edilirken; son 6 ay içinde alt ekstremitede travma ya da cerrahi öyküsüne sahip, bilişsel yetersizliği tespit edilmiş (Standardize Mini Mental Test Skoru 24 puanın altında), nörolojik bir hastalık tanısı almış bireyler çalışma dışı bırakıldı.

Çalışmamızın yapılabilmesi için Hacettepe Üniversitesi Tıp Fakültesi Girişimsel Olmayan Klinik Araştırmalar Etik Kurulu'ndan 11.10.2016 tarih ve GO 16/589 - 11 karar numaralı izin ve onay alındı. Bireyler ilgili etik kurulun ön gördüğü aydınlatılmış onam formunu doldurduktan sonra çalışmaya dahil edildi.

Tüm bireylerin yaş, cinsiyet, boy, vücut ağırlığı, vücut kütle indeksi (VKİ) gibi demografik verileri kaydedilerek kronik hastalıkları ve kullandıkları ilaçlar sorgulandı. Bireyler yaşadıkları yere (toplum içinde ya da huzurevinde); yaş aralıklarına (65-74 yaş arası ya da 75 yaş ve üstü); cinsiyetlerine (kadın ya da erkek) ve vücut kütle indekslerine (VKİ) göre $\left(18.5 \mathrm{~kg} / \mathrm{m}^{2}<\mathrm{VKİ}<25 \mathrm{~kg} / \mathrm{m}^{2}\right.$ normal, $25 \mathrm{~kg} /$ $\mathrm{m}^{2} \leq$ VKI $<30 \mathrm{~kg} / \mathrm{m}^{2}$ aşırı kilolu; VKI $\geq 30 \mathrm{~kg} / \mathrm{m}^{2}$ obez 
olarak kabul edildi) gruplara ayrilarak, gruplar plantar hafif dokunma-basınç duyusu açısından karşılaştırıldı.

Plantar hafif dokunma-basınç duyusu, ayağın topuk, orta ayağın mediali, orta ayağın laterali, birinci, üçüncü ve beşinci metatars başı ile birinci, üçüncü ve beşinci parmak olmak üzere dokuz bölgesinden ölçüldü (Şekil 1). Monofilament testi, SemmesWeinstein ${ }^{\circledR}$ (NorthCoast Medical, Inc, ABD) tipi eşit uzunluk ve farklı çaplarda cilde standart basinç uygulayan 6 farklı monoflament (seviye 2,$83 ; 3,61 ; 4,31 ; 4,56 ; 5,07 ; 6,65$ ) kullanilarak her iki ayağın 9 farklı bölgesinde koruyucu duyu kaybını test etmek için uygulandı. Değerlendirilen birey sırtüstü gözleri kapalı olarak uzanırken monoflamentlerin bükülmesine yetecek basınç 1 saniye boyunca uyguland, bireyden uygulanan basıncı hissettiğinde bildirmesi ve nerede hissettiğini göstermesi istendi. Hissedip hissetmediğini ve lokalizasyonunu doğru tarif edebildiği en küçük değerdeki monofilament kaydedildi (6).

\section{İstatistiksel Analiz}

İstatistiksel analizler Windows tabanlı SPSS 15.0 paket programı ile yapıldı, $\mathrm{p}<0,05$ değeri anlamlı kabul edildi. Değişkenlerin normal dağılıma uygunluğu görsel (histogram ve olasılık grafikleri) ve analitik yöntemler (Kolmogorov-Smirnov/Shapiro-Wilk testleri) kullanılarak incelendi. Tanımlayıcı analizler ortalama ve standart sapmalar kullanılarak verildi. Normal dağılmayan plantar duyu değişkeni ikili gruplar arasında Mann-Whitney U testi kullanılarak, üçlü gruplar arasında ise Kruskal-Wallis testi kullanılarak karşılaştırıldı.

\section{BULGULAR}

Çalışmamız yaş ortalaması 74,38 $\pm 6,59$ yıl 60 kadın, 35 erkek olmak üzere 95 bireyle gerçekleştirildi. Bireylerin yaş, cinsiyet ve vücut kütle indeksi ile ilgili değerler Tablo 1'de gösterilmiştir.

Tablo 2'de Toplum içinde ve huzurevinde yaşayan bireylerin plantar hafif dokunma-basınç duyusu verilerinin ortalama ve standart sapmaları ile karşılaştırma sonuçları gösterilmektedir. Huzurevinde yaşayan bireylerin toplum içinde yaşayanlara göre sağ ve sol topukta plantar hafif dokunma-basınç duyularının azalmış olduğu bulundu $(p<0,05)$. İki grup arasında diğer plantar bölgelerin hafif dokunma-basınç duyusu açısından anlamlı bir fark olmadığı bulundu ( $\mathrm{p}>0,05)$ (Tablo 2).

65-75 yaş arası ile 75 yaş ve üzeri bireylerin plantar hafif dokunma-basınç duyusu verilerinin ortalama ve standart sapmaları ile karşılaştırma sonuçları Tablo 3'de verilmiştir. 75 yaş ve üstü bireylerin 65-75 yaşları arasında olanlara göre sol ayakta birinci, üçüncü ve beşinci metatarsta; sağ ve sol ayakta topukta plantar hafif dokunma-basınç duyularının azalmış olduğu bulundu $(\mathrm{p}<0,05)$. İki grup arasında diğer plantar bölgelerin hafif dokunma-basınç duyusu açısından anlamlı bir fark olmadığı bulundu ( $\mathrm{p}>0,05)$ (Tablo 3).

Çalışmaya dahil edilen kadın ve erkeklerin plantar hafif dokunma-basınç duyusu verilerinin ortalama ve standart sapmaları ile karşılaştırma sonuçları Tablo 4'de verilmiştir. Erkeklerin kadınlara göre sol ayakta topukta plantar hafif dokunma-basınç duyularının azalmış olduğu bulundu $(p<0,05)$. İki grup arasında diğer plantar bölgelerin hafif dokunma-basınç duyusu açısından anlamlı bir fark olmadığı bulundu ( $>0,05)$ (Tablo 4).

Tablo 5'de vücut kütle indeksine göre normal, aşırı kilolu ve obez bireylerin plantar hafif dokunma-basınç duyusu verilerinin ortalama ve standart sapmaları ile karșılaștırma sonuçları gösterilmektedir. Gruplar arasında plantar hafif dokunma-basınç duyusu açısından anlamlı bir fark olmadığı bulundu ( $p>0,05)$ (Tablo 5).

Tablo 1: Bireylerin demografik bilgileri.

\begin{tabular}{lc}
\hline Demografik & $\mathbf{n}=\mathbf{9 5}$ \\
\hline Yaş $(\mathrm{yll})(\mathrm{Ort} \pm \mathrm{SS})$ & $74,38 \pm 6,59$ \\
\hline VKİ $\left(\mathrm{kg} / \mathrm{m}^{2}\right)(\mathrm{Ort} \pm \mathrm{SS})$ & $27.84 \pm 4,25$ \\
\hline Cinsiyet $(\mathrm{K} / \mathrm{E})$ & $60 / 35$ \\
\hline
\end{tabular}

Ort: ortalama, SS: Standart sapma, VKİ: Vücut Kütle İndeksi, kg: Kilogram, m: Metre, K: Kadın, E: Erkek.

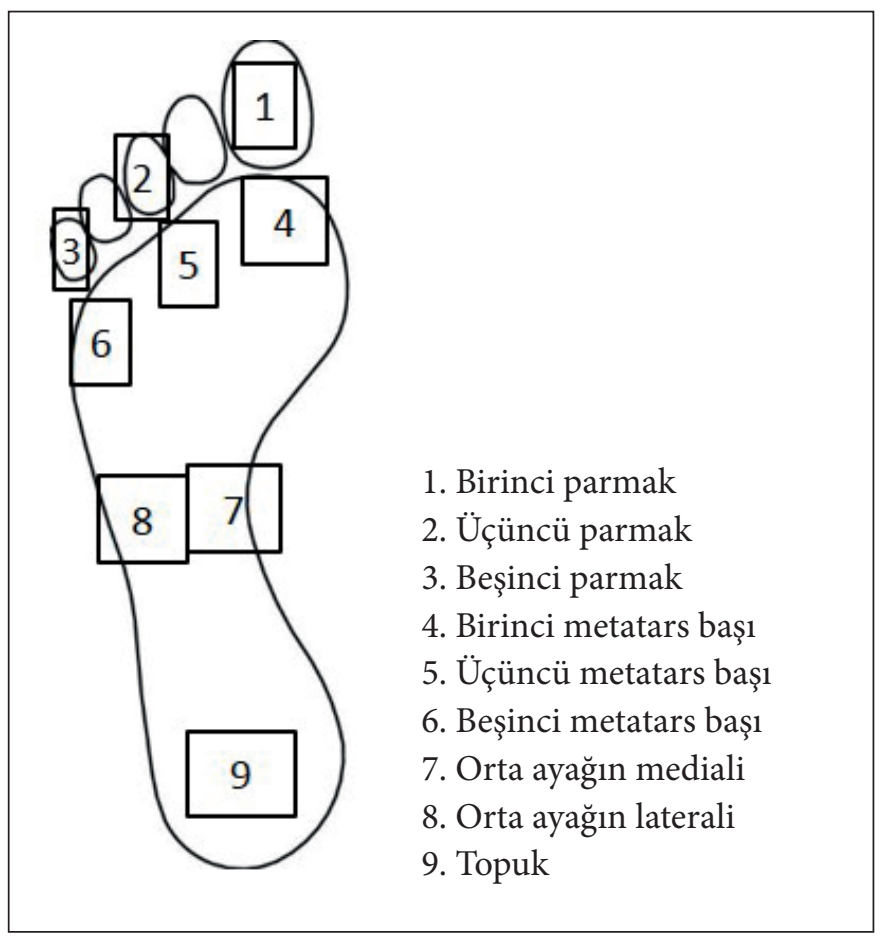

Şekil 1: Duyu değerlendirmesi yapılan plantar bölgeler. 
Tablo 2: Toplum içinde ve Huzurevinde yaşayan bireylerin plantar hafif dokunma-basınç duyularının karşılaştırılması.

\begin{tabular}{|c|c|c|c|c|}
\hline $\begin{array}{l}\text { Ayak Bölgesine Göre Eşik } \\
\text { Monofilament Seviyesi }\end{array}$ & & $\begin{array}{l}\text { Toplum İçinde Yaşayanlar } \\
(\mathrm{n}=55) \quad(\text { Ort } \pm \mathrm{SS})\end{array}$ & $\begin{array}{l}\text { Huzurevinde Yaşayanlar } \\
\quad(n=40) \quad(\text { Ort } \pm S S)\end{array}$ & $\mathbf{p}$ \\
\hline \multirow{2}{*}{ 1. Parmak } & Sol Ayak & $4,73 \pm 0,78$ & $4,67 \pm 0,82$ & 0,986 \\
\hline & Sağ Ayak & $4,71 \pm 0,74$ & $4,70 \pm 0,86$ & 0,983 \\
\hline \multirow{2}{*}{ 3. Parmak } & Sol Ayak & $4,77 \pm 0,78$ & $4,71 \pm 0,95$ & 0,339 \\
\hline & Sağ Ayak & $4,74 \pm 0,78$ & $4,65 \pm 0,87$ & 0,563 \\
\hline \multirow{2}{*}{ 5. Parmak } & Sol Ayak & $4,76 \pm 0,82$ & $4,72 \pm 0,96$ & 0,672 \\
\hline & Sağ Ayak & $4,76 \pm 0,82$ & $4,57 \pm 0,76$ & 0,605 \\
\hline \multirow{2}{*}{ 1. Metatars } & Sol Ayak & $4,70 \pm 0,73$ & $4,98 \pm 0,99$ & 0,575 \\
\hline & Sağ Ayak & $4,82 \pm 0,86$ & $4,80 \pm 0,82$ & 0,124 \\
\hline \multirow{2}{*}{ 3. Metatars } & Sol Ayak & $4,75 \pm 0,77$ & $5,07 \pm 1,03$ & 0,156 \\
\hline & Sağ Ayak & $4,89 \pm 0,91$ & $5,02 \pm 0,99$ & 0,338 \\
\hline \multirow{2}{*}{ 5. Metatars } & Sol Ayak & $4,78 \pm 0,81$ & $4,95 \pm 1,03$ & 0,285 \\
\hline & Sağ Ayak & $4,91 \pm 0,91$ & $4,89 \pm 0,92$ & 0,495 \\
\hline \multirow{2}{*}{ Orta Ayak Mediali } & Sol Ayak & $4,71 \pm 0,73$ & $4,52 \pm 0,63$ & 0,282 \\
\hline & Sağ Ayak & $4,81 \pm 0,85$ & $4,58 \pm 0,76$ & 0,149 \\
\hline \multirow{2}{*}{ Orta Ayak Laterali } & Sol Ayak & $4,81 \pm 0,81$ & $4,77 \pm 0,89$ & 0,899 \\
\hline & Sağ Ayak & $4,89 \pm 0,91$ & $4,75 \pm 0,85$ & 0,489 \\
\hline \multirow{2}{*}{ Topuk } & Sol Ayak & $5,18 \pm 0,89$ & $5,74 \pm 0,93$ & $0,002^{\star}$ \\
\hline & Sağ Ayak & $5,30 \pm 0,95$ & $5,71 \pm 0,92$ & $0,025^{\star}$ \\
\hline
\end{tabular}

${ }^{*} \mathrm{p}<0,05$ Ort: ortalama, SS: Standart sapma.

Tablo 3: 65-75 yaş arası ile 75 yaş ve üzeri bireylerin plantar hafif dokunma-basınç duyularının karşılaştırılması.

\begin{tabular}{|c|c|c|c|c|}
\hline \multirow{2}{*}{\multicolumn{2}{|c|}{$\begin{array}{l}\text { Ayak Bölgesine Göre Eşik } \\
\text { Monofilament Seviyesi }\end{array}$}} & \multirow{2}{*}{$\begin{array}{c}\text { 65-75 yaş arası } \\
(\mathrm{n}=47) \quad(\text { Ort } \pm \text { SS })\end{array}$} & 75 yaş ve üzeri & \multirow{2}{*}{$\mathbf{p}$} \\
\hline & & & $(\mathrm{n}=48) \quad($ Ort $\pm S S)$ & \\
\hline \multirow{2}{*}{ 1. Parmak } & Sol Ayak & $4,64 \pm 0,78$ & $4,77 \pm 0,81$ & 0,145 \\
\hline & Sağ Ayak & $4,60 \pm 0,70$ & $4,81 \pm 0,86$ & 0,128 \\
\hline \multirow{2}{*}{ 3. Parmak } & Sol Ayak & $4,66 \pm 0,84$ & $4,83 \pm 0,86$ & 0,182 \\
\hline & Sağ Ayak & $4,66 \pm 0,84$ & $4,74 \pm 0,80$ & 0,402 \\
\hline \multirow{2}{*}{ 5. Parmak } & Sol Ayak & $4,67 \pm 0,81$ & $4,81 \pm 0,93$ & 0,254 \\
\hline & Sağ Ayak & $4,60 \pm 0,72$ & $4,75 \pm 0,87$ & 0,420 \\
\hline \multirow{2}{*}{ 1. Metatars } & Sol Ayak & $4,63 \pm 0,67$ & $4,99 \pm 0,98$ & $0,021^{*}$ \\
\hline & Sağ Ayak & $4,74 \pm 0,83$ & $4,88 \pm 0,84$ & 0,115 \\
\hline \multirow{2}{*}{ 3. Metatars } & Sol Ayak & $4,69 \pm 0,74$ & $5,08 \pm 1,00$ & $0,019^{\star}$ \\
\hline & Sağ Ayak & $4,87 \pm 0,96$ & $5,03 \pm 0,93$ & 0,188 \\
\hline \multirow{2}{*}{ 5. Metatars } & Sol Ayak & $4,70 \pm 0,81$ & $5,00 \pm 0,98$ & $0,048^{\star}$ \\
\hline & Sağ Ayak & $4,76 \pm 0,78$ & $5,04 \pm 1,00$ & 0,149 \\
\hline \multirow{2}{*}{ Orta Ayak Mediali } & Sol Ayak & $4,54 \pm 0,63$ & $4,72 \pm 0,75$ & 0,093 \\
\hline & Sağ Ayak & $4,70 \pm 0,81$ & $4,79 \pm 0,82$ & 0,090 \\
\hline \multirow{2}{*}{ Orta Ayak Laterali } & Sol Ayak & $4,68 \pm 0,73$ & $4,90 \pm 0,93$ & 0,154 \\
\hline & Sağ Ayak & $7,70 \pm 0,78$ & $4,96 \pm 0,96$ & 0,126 \\
\hline \multirow{2}{*}{ Topuk } & Sol Ayak & $5,20 \pm 0,89$ & $5,63 \pm 0,96$ & $0,041^{*}$ \\
\hline & Sağ Ayak & $5,23 \pm 0,93$ & $5,71 \pm 0,93$ & $0,010^{*}$ \\
\hline
\end{tabular}

${ }^{*} \mathrm{p}<0,05$ Ort $=$ ortalama, $\mathrm{SS}=$ Standart sapma. 
Tablo 4: Kadın ve erkeklerin plantar hafif dokunma-basınç duyularının karşılaştırılması.

\begin{tabular}{|c|c|c|c|c|}
\hline \multirow{2}{*}{\multicolumn{2}{|c|}{$\begin{array}{l}\text { Ayak Bölgesine Göre Eşik } \\
\text { Monofilament Seviyesi }\end{array}$}} & \multirow{2}{*}{$\begin{array}{c}\text { Kadın } \\
(\mathrm{n}=60) \quad(\text { Ort } \pm \mathrm{SS})\end{array}$} & Erkek & \multirow{2}{*}{$\mathbf{p}$} \\
\hline & & & $(\mathrm{n}=35) \quad($ Ort \pm SS $)$ & \\
\hline \multirow{2}{*}{ 1. Parmak } & Sol Ayak & $4,63 \pm 0,69$ & $4,84 \pm 0,95$ & 0,320 \\
\hline & Sağ Ayak & $4,69 \pm 0,72$ & $4,74 \pm 0,90$ & 0,962 \\
\hline \multirow{2}{*}{ 3. Parmak } & Sol Ayak & $4,63 \pm 0,73$ & $4,94 \pm 1,00$ & 0,192 \\
\hline & Sağ Ayak & $4,65 \pm 0,73$ & $4,78 \pm 0,95$ & 0,980 \\
\hline \multirow{2}{*}{ 5. Parmak } & Sol Ayak & $4,66 \pm 0,78$ & $4,88 \pm 1,01$ & 0,418 \\
\hline & Sağ Ayak & $4,67 \pm 0,81$ & $4,70 \pm 0,79$ & 0,811 \\
\hline \multirow{2}{*}{ 1. Metatars } & Sol Ayak & $4,80 \pm 0,88$ & $4,84 \pm 0,83$ & 0,653 \\
\hline & Sağ Ayak & $4,77 \pm 0,82$ & $4,89 \pm 0,86$ & 0,382 \\
\hline \multirow{2}{*}{ 3. Metatars } & Sol Ayak & $4,88 \pm 0,89$ & $4,90 \pm 0,92$ & 0,744 \\
\hline & Sağ Ayak & $4,79 \pm 0,83$ & $5,22 \pm 1,06$ & 0,058 \\
\hline \multirow{2}{*}{ 5. Metatars } & Sol Ayak & $4,79 \pm 0,85$ & $4,95 \pm 1,01$ & 0,803 \\
\hline & Sağ Ayak & $4,85 \pm 0,82$ & $4,99 \pm 1,05$ & 0,662 \\
\hline \multirow{2}{*}{ Orta Ayak Mediali } & Sol Ayak & $4,60 \pm 0,70$ & $4,69 \pm 0,69$ & 0,246 \\
\hline & Sağ Ayak & $4,63 \pm 0,73$ & $4,86 \pm 0,94$ & 0,216 \\
\hline \multirow{2}{*}{ Orta Ayak Laterali } & Sol Ayak & $4,72 \pm 0,79$ & $4,92 \pm 0,93$ & 0,291 \\
\hline & Sağ Ayak & $4,72 \pm 0,80$ & $5,01 \pm 1,00$ & 0,139 \\
\hline \multirow{2}{*}{ Topuk } & Sol Ayak & $5,25 \pm 0,88$ & $5,70 \pm 1,00$ & $0,041^{\star}$ \\
\hline & Sağ Ayak & $5,35 \pm 0,93$ & $5,68 \pm 0,98$ & 0,124 \\
\hline
\end{tabular}

${ }^{*} \mathrm{p}<0,05$ Ort: ortalama, SS: Standart sapma.

Tablo 5: Vücut kütle indeksine göre normal, aşırı kilolu ve obez bireylerin plantar hafif dokunma-basınç duyularının karşılaștırılması.

\begin{tabular}{|c|c|c|c|c|c|}
\hline \multirow{2}{*}{$\begin{array}{l}\text { Ayak Bölgesine Göre Eşik } \\
\text { Monofilament Seviyesi }\end{array}$} & & Normal & Aşırı Kilolu & Obez & \multirow{2}{*}{$\mathbf{p}$} \\
\hline & & $(\mathrm{n}=23) \quad($ Ort \pm SS $)$ & $(\mathrm{n}=44) \quad($ Ort \pm SS $)$ & $(\mathrm{n}=28) \quad($ Ort $\pm \mathrm{SS})$ & \\
\hline \multirow{2}{*}{ 1. Parmak } & Sol Ayak & $4,90 \pm 0,98$ & $4,57 \pm 0,71$ & $4,75 \pm 0,74$ & 0,489 \\
\hline & Sağ Ayak & $4,89 \pm 0,99$ & $4,63 \pm 0,75$ & $4,67 \pm 0,64$ & 0,839 \\
\hline \multirow{2}{*}{ 3. Parmak } & Sol Ayak & $4,92 \pm 1,09$ & $4,69 \pm 0,78$ & $4,69 \pm 0,74$ & 0,944 \\
\hline & Sağ Ayak & $4,95 \pm 1,05$ & $4,58 \pm 0,69$ & $4,68 \pm 0,76$ & 0,591 \\
\hline \multirow{2}{*}{ 5. Parmak } & Sol Ayak & $5,11 \pm 1,15$ & $4,53 \pm 0,57$ & $4,77 \pm 0,93$ & 0,347 \\
\hline & Sağ Ayak & $5,09 \pm 1,07$ & $4,53 \pm 0,63$ & $4,58 \pm 0,69$ & 0,210 \\
\hline \multirow{2}{*}{ 1. Metatars } & Sol Ayak & $5,06 \pm 0,99$ & $4,70 \pm 0,78$ & $4,80 \pm 0,84$ & 0,290 \\
\hline & Sağ Ayak & $5,11 \pm 1,06$ & $4,68 \pm 0,69$ & $4,77 \pm 0,82$ & 0,470 \\
\hline \multirow{2}{*}{ 3. Metatars } & Sol Ayak & $5,12 \pm 1,05$ & $4,72 \pm 0,77$ & $4,96 \pm 0,93$ & 0,434 \\
\hline & Sağ Ayak & $5,21 \pm 1,09$ & $4,79 \pm 0,86$ & $4,98 \pm 0,92$ & 0,335 \\
\hline \multirow{2}{*}{ 5. Metatars } & Sol Ayak & $5,21 \pm 1,11$ & $4,64 \pm 0,75$ & $4,90 \pm 0,89$ & 0,147 \\
\hline & Sağ Ayak & $5,21 \pm 1,09$ & $4,73 \pm 0,80$ & $4,91 \pm 0,87$ & 0,642 \\
\hline \multirow{2}{*}{ Orta Ayak Mediali } & Sol Ayak & $4,93 \pm 0,95$ & $4,50 \pm 0,58$ & $4,59 \pm 0,55$ & 0,209 \\
\hline & Sağ Ayak & $4,96 \pm 1,03$ & $4,61 \pm 0,70$ & $4,68 \pm 0,77$ & 0,418 \\
\hline \multirow{2}{*}{ Orta Ayak Laterali } & Sol Ayak & $5,11 \pm 1,05$ & $4,65 \pm 0,70$ & $4,77 \pm 0,81$ & 0,324 \\
\hline & Sağ Ayak & $5,11 \pm 1,04$ & $4,67 \pm 0,75$ & $4,85 \pm 0,91$ & 0,206 \\
\hline \multirow{2}{*}{ Topuk } & Sol Ayak & $5,87 \pm 0,99$ & $5,22 \pm 0,87$ & $5,35 \pm 1,02$ & 0,088 \\
\hline & Sağ Ayak & $5,88 \pm 0,99$ & $5,33 \pm 0,85$ & $5,35 \pm 0,95$ & 0,101 \\
\hline
\end{tabular}

Ort: ortalama, SS: Standart sapma. 


\section{TARTIŞMA}

Yaşlı bireylerde yaş, cinsiyet, obezite ve huzurevinde yaşamanın plantar duyuya etkisini araştırmak amacıyla gerçekleştirilen çalışmamız 75 yaş ve üstü bireylerin 65-75 yaşları arasında olanlara göre metatarsal alan ve topukta, erkeklerin kadınlara göre ve huzurevinde yaşayanların toplum içinde yaşayanlara göre topukta plantar hafif dokunma-basınç duyularının azaldığını göstermiştir. Bununla birlikte, normal, aşırı kilolu ve obez olan yaşlı bireyler arasında plantar hafif dokunma-basınç duyusu açısından anlamlı bir fark olmadığı ortaya koyulmuştur.

Yaşın ilerlemesi ile fizyolojik, yapısal ve metabolik değişikliklere bağlı olarak dokunma duyusu azalır (2). 65 yaş üstü bireylerde yaşın ilerlemesiyle somatosensorial bozuklukların oranının arttığ 1 bilinmektedir (7). Perry (6), 72-73 yaşları arasındaki bireylerin 65-71 yaş arası ile karşılaştırıldığında plantar bölgede vibrasyon duyusunun azalmış olduğunu, ancak bu iki yaş grubunun plantar hafif dokunma-basınç duyusu açısından benzer eşiklere sahip olduğunu bildirmiştir. Yümin ve ark. (13), 45-65 ve 65 yaş üstü grupların, 25-44 yaş arası bireylerle karşılaştırıldığında plantar hafif dokunma-basınç duyularının azalmış olduğunu, bununla birlikte $45-65$ yaş arası ve 65 yaş üstü bireylerin plantar hafif dokunma-basınç duyularının benzer olduğunu göstermiştir. Bizim sonuçlarımız ise 65-75 yaş arası ile karşılaştırıldığında, 75 yaş ve üstü bireylerin plantar hafif dokunma-basınç duyularının azalmış olduğunu ortaya koymuştur. Bu bilgiler 1şığında, yaşlı popülasyonda plantar hafif dokunma-basınç duyusu açısından belirgin değişikliğin 75 yaşından itibaren ortaya çıtıtı̆̆ düşünülebilir.

Kadınların dokunma duyularının erkeklere göre daha iyi olduğu gösterilmiş olmakla birlikte, Deshpande ve ark. (8), ayaktaki vibrasyon algı eşiğinin erkeklerde kadınlara göre daha yüksek bulunmasının nedenini aradaki boy farkına bağlamışlardır. Bizim çalışmamız erkeklerde kadınlara göre topuktaki plantar hafif dokunma-basınç duyusunun azalmış olduğunu ortaya koymuştur. Cinsiyetler arasında görülen plantar duyu farkının topukta belirgin olmasının nedeni, plantar bölgede yaşla beraber artan yumuşak doku sertlik ve kalınlığının topukta diğer bölgelere göre daha fazla olması olabilir (1). Plantar duyunun azalması ile ilişkili olduğu bilinen yumuşak doku kalınlığı ve sertliğindeki artışın cinsiyetler arasındaki olası farklılıklarını araştıran çalışmalara ihtiyaç vardır.

Çalışmamızda, huzurevinde yaşayan yaşlı bireylerin plantar hafif dokunma-basınç duyularının toplum içinde yaşayanlara göre topuk bölgesinde azaldığını göstermiştir. $\mathrm{Bu}$ farklılık cinsiyetler arası plantar duyu farkına benzer bir biçimde topuktaki plantar yumuşak doku sertlik ve kalınlık artışına bağlanabilir. Huzurevinde ve toplum içinde yaşayan yaşlı bireylerin ayak bakım alışkanlıkları arasındaki olası fark, huzurevinde yaşayanlarda topukta hiperkeratoz gelişiminin daha fazla olmasına sebep oluyor olabilir. Bunun yanında, huzurevinde yaşayan yaşlı bireylerin toplum içinde yaşayanlara göre mobilite ve aktivite seviyelerinin daha düşük olduğu bilinmektedir (15). Maitre ve ark. (5), düzenli fiziksel aktivitenin dokunma duyusunu geliştirebileceğini bildirmiştir. Bu açıdan bakıldığında, huzurevinde yaşayan yaşı bireylerin plantar hafif dokunma-basınç duyularındaki azalma yetersiz fiziksel aktivite düzeyi ile açıklanabilir.

Farklı yaş gruplarında yapılan ve obez bireylerin plantar duyularının obez olmayanlara göre azalmış olduğunu gösteren çalışmalar, obezitenin ayak tabanında aşırı yüklenmeye neden olduğu, bunun da dokunma duyusunun hassasiyetinin azalmasina neden olduğu üzerinde durmuşlardır $(12,13,17)$. Bu bulguların aksine, bizim sonuçlarımız normal, aşırı kilolu ve obez olan yaşlı bireylerin plantar hafif dokunma- basınç duyu eşiklerinin benzer olduğunu göstermiştir. Yaşlanmayla birlikte plantar duyunun azalmasına neden olan fizyolojik, mekanik ve metabolik diğer etkenlerin ortaya çıkması, yaşlı popülasyonda obezitenin plantar duyu üzerindeki etkisinin açığa çıkarılabilmesinin önüne geçmiş olabilir.

Çalışmamızın bazı kısıtlılıkları bulunmaktadır. Yaşlı bireylerde plantar duyuyu etkileyebilecek plantar yumuşak dokuların mekanik özellikleri, kutanöz reseptörlerdeki fizyolojik değişiklikler, ayak postürü ve deformiteleri gibi etkenlerin demografik özelliklerle ilişkileri değerlendirilmemiştir.

$\mathrm{Bu}$ çalışma, yaşlı bireylerde ileri yaş, erkek cinsiyet ve huzurevinde yaşamanın plantar duyunun azalmasında etkili olabileceğini ortaya koymuştur. Bununla birlikte normal, aşırı kilolu ve obez olan yaşlı bireylerin plantar hafif dokunma-basınç duyularının benzer olduğu görülmüştür. Demografik açıdan risk taşıyan yaşlı popülasyonda, plantar duyuyu etkileyebilecek faktörler değerlendirilmeli ve tedavi süreçlerinde dikkate alınmalıdır. Sağlık çalışanları, yaşlı popülasyon içerisinde 75 yaş üzerinde, erkek ve huzurevinde yaşamakta olanların plantar duyu azalmasına bağlı olarak yürüyüş bozuklukları, denge ve düşme problemleri açısından daha fazla risk taşıdığını göz önünde bulundurmalı, bu konularla ilgili gereken önlemler alınmalıdır. Demografik açıdan risk taşıyan bu grubun tedavi programlarına plantar duyu eğitimi eklenmeli, bu bireylerin kendileri, aileleri ya da bakım verenler ayak bakımı konusunda bilgilendirilmelidir. 


\section{KAYNAKLAR}

1. Peters RM, McKeown MD, Carpenter MG, Inglis JT. Losing touch: Age-related changes in plantar skin sensitivity, lower limb cutaneous reflex strength, and postural stability in older adults. J Neurophysiol. 2016;116(4):1848-1858.

2. Decorps J, Saumet JL, Sommer P, Sigaudo-Roussel D, Fromy B. Effect of ageing on tactile transduction processes. Ageing Res Rev. 2014;13:90-99.

3. Cruz-Almeida Y, Black ML, Christou EA, Clark DJ. Sitespecific differences in the association between plantar tactile perception and mobility function in older adults. Front Aging Neurosci. 2014;6(68):103-7.

4. Massion J. Postural control system. Curr Opin Neurobiol. 1994;4:877-887.

5. Maitre J, Paillard TP. Influence of the plantar cutaneous information in postural regulation depending on the age and the physical activity status. Front Hum Neurosci. 2016;10:409.

6. Perry SD. Evaluation of age-related plantar-surface insensitivity and onset age of advanced insensitivity in older adults using vibratory and touch sensation tests. Neurosci Lett. 2006;392:62-67.

7. Kozłowska A. Studying tactile sensitivity-population approach. Anthropol Rev. 1998;61:3-30.

8. Deshpande N, Metter EJ, Ling S, Conwit R, Ferrucci L. Physiological correlates of age-related decline in vibrotactile sensitivity. Neurobiol Aging. 2008;29(5):765-773.

9. Gregor MF, Hotamisligil GS. Inflammatory mechanisms in obesity. Annu Rev Immunol. 2011;29:415-45.
10. Thomas D, Elliott EJ. Low glycaemic index, or low glycaemic load, diets for diabetes mellitus. Cochrane Database Syst Rev. 2009;1:CD006296

11. Butterworth PA, Urquhart DM, Landorf KB, Wluka AE, Cicuttini FM, Menz HB. Foot posture, range of motion and plantar pressure characteristics in obese and non-obese individuals. Gait Posture. 2015;41(2):465-469.

12. Wu X, Madigan ML. Impaired plantar sensitivity among the obese is associated with increased postural sway. Neurosci Lett. 2014;583:49-54.

13. Yümin ET, Şimşek TT, Sertel M, Ankaralı H. The effect of age and body mass index on plantar cutaneous sensation in healthy women. J Phys Ther Sci. 2016;28(9):2587-2595.

14. Giuliani CA, Gruber-Baldini AL, Park NS, Schrodt LA, Rokoske F, Sloane PD, et al. Physical performance characteristics of assisted living residents and risk for adverse health outcomes. Gerontologist. 2008;48(2):203-212.

15. Topuz S, De Schepper J, Ülger Ö, Roosen P. Do mobility and life setting affect falling and fear of falling in elderly people? Top Geriatr Rehabil. 2014;30(3):223-229.

16. Odding E, Valkenburg HA, Grobbee DE, Hofman A, Pols HA. Locomotor disability in the elderly; the ERGO Study (Erasmus Rotterdam Health and the Elderly). ERGO Study Group. Ned Tijdschr Geneeskd. 1995;139(41):2096-100.

17. da Rocha ES, Bratz DTK, Gubert LC, de David A, Carpes FP. Obese children experience higher plantar pressure and lower foot sensitivity than non-obese. Clin Biomech. 2014;29(7):822827. 
